\title{
Renal Tumor-Reactive Autologous Tumor Infiltrating Lymphocyte
}

National Cancer Institute

\section{Source}

National Cancer Institute. Renal Tumor-Reactive Autologous Tumor Infiltrating

Lymphocyte. NCl Thesaurus. Code C48817.

Tumor infiltrating lymphocytes (TIL) harvested directly from infiltrate of a patient's renal tumor and cultured with interleukin-2 to expand the TIL cell population. Tumor infiltrating lymphocytes have specific activity ag ainst the tumor from which they are derived. Introducing these renal tumor-reactive autologous tumor infiltrating lymphocytes back into the same patient may enhance a cytotoxic T-cell-mediated immune response against the renal cancer cells. 